\title{
SEJARAH PENGGUNAAN UANG SEJAK MASA RASULULLAH SAW \\ SAMPAI SEKARANG
}

\author{
Fadilla \\ Dosen Perbankan Syariah STEBIS IGM Palembang \\ Email : haninfadilla423@gmail.com
}

\begin{abstract}
ABSTRAK
Perkembangan teknologi telah mendorong kita untuk beradaptasi dalam segala hal termasuk dalam transaksi keuangan. Penelitian ini bertujuan untuk mengetahui macam-macam alat pertukaran dari masa Rasulullah SAW sampai sekarang yaitu era milenial. Metode penelitian yang digunakan adalah library research. Hasil penelitian ini menunjukkan bahwa pada masa Rasulullah pertukaran uang menggunakan emas dan perak (dinnar dan dirham) hal ini berlajut sampai pada masa khalifah dan Bani Umayah dan Abbasiyah. Pada Masa Fathimiyah dirhamdirham campran banyak dijadikan uang. Pada masa Shalahudin Al-Ayyubi bahan baku emas sudah tidak mencukupi untuk pencetakan dinar hal ini disebabkan karena peperangan. Akhirnya pada saat perang dunia pertama tahun 1914 Turki dan negara-negara lainnya memberlakukan uang kertas sebagaialat pembayaran yang sah dan membatalkan berlakuknya uang emas dan perak. Pada masa sekarang dengan kecanggihan teknologi sudah banyak yang menggunakan uang elektronik (E-Money) dikarenakan lebih simpel dan mudah dalam penggunaannya.
\end{abstract}

Kata kunci :Alat tukar (emas dan perak), Masa Rasulullah sampai sekarang, E-money

\section{DASAR PEMIKIRAN}

\section{Latar Belakang}

Pada masa lalu kira sering melakukan pembayaran (transaksi) dengan cara tukar menukar uang dengan barang, barang dan barang. Sekarang pertukaran tidak hanya dilakukan dengan kedua benda itu melainkan menggunakan nilai uang yang terdapat di dalam bank yang ada sekarang. Negara maju seperti jepang,Cina, USA pembayaran yang mereka lakukan menggunakan salah satu aplikasi dalam handphone kita biasa disebut dengan E-Money.

Dalam ketentuan Peraturan Bank Indonesia Nomor 11/12/PBI/2009 tentang Uang Elektronik (Electronic Money) dalam ketentuan Pasal 1 Ayat 3, "Uang Elektronik (Electronic Money) adalah alat pembayaran yang diterbitkan atas dasar nilai uang yang disetor terlebih dahulu oleh pemegang kepada penerbit" Nilai uang disimpan secara elektronik dalam suatu media server atau chip yang digunakan sebagai alat pembayaran kepada pedagang yang bukan merupakan penerbit uang elektronik tersebut. Nilai uang elektronik yang pemegang dan dikelola oleh penerbit 
bukan merupakan simpanan sebagaimana dimaksud dalam undang-undang yang mengatur mengenai perbankan. (Sofyan, 2015 : 3) Penelitian ini berusaha untuk mengungkapkan sejarah penggunaan uang dari zaman Rasulullah sampai sekarang. Oleh sebab itu judul penelitian ini adalah sejarah penggunaan uang sejak masa Rasulullah sampai sekarang.

\section{Rumusan Masalah}

Berdasarkan latar belakang di atas maka rumusan masalah dalam penelitian ini adalah: "Apa alat tukar dalam transaksi jual-beli pada sejak zaman Rasulullah sampai sekarang?."

\section{Tujuan Penelitian}

Adapun tujuan penelitian ini adalah untuk mengetahui alat tukar dari masa ke masa terutama pada masa Rasulullah hingga saat ini.

\section{Penelitian Terdahulu}

Sebelum peneliti melakukan penelitian ini ada beberapa peneliti terdahulu yang telah melakukan penelitian yang sama salah satunya adalah Resi Susanti. Beliau melakukan penelitian yang berjudul Sejarah Transformasi Uang dalam Islam. Penelitian ini dipublikasikan pada tahun 2017.

Afif dan Ari melakukan penelitian yang berjudul Electronic Money (e-money) dalam perspektif Maqashid Syariah. Penelitian ini dipublikasikan pada tahun 2017. Hasil penelitian ini menunjukkan bahwa secara umum uang elektronik telah sesuai dengan maqashid syariah. Kesesuaian ini didapat dengan terpenuhinya prinsip memelihara harta dan kemaslahatan. (Muamar dan Ari, 2017 : 75)

\section{PEMBAHASAN}

\section{Definisi Uang menurut Islam}

Secara etimologi, definisi uang (nuqud) adalah :

1. Al-Naqdu :yaitu yang baik dari dirham

2. Al-Naqduyaitu tunai (lawan dari tunda) yakni memberikan bayaran dengan segera. Dalam hadist jabir disebutkan bahwa "Naqadani at-tsaman " yakni membayarku dengan tunai kemudian digunakan barang yang sudah dibayarkan termasuk penggunaan kata masdar. 
Orang Arab padda zaman Rasulullah tidak mengenal kata Nuqud mereka menggunakan kata Dinar dan dirham sebagai alat tukar. Sedangkat fulus adalah uang tembaga yang juga merupakan uang tambahan untuk membeli barang-barang yang murah. Adapun pengertian dinar dan dirham adalah :

a. Dinar merupakan barasal dari bahasa romawi yaitu kata Denarius yang artinya emas cetakan

b. Adapun dirham berasal dari bahasa yunani yaitu Drachma yang berarti perak cetakan.

Cendikiawan muslim Al-ghazali dan Ibn Khaldun uang dapat diartikan sebagai segala sesuatu yang digunakan sebagai :

1. standar ukuran nilai harga

2. Media transaksi

3. Media penyimpan nilai

Dari penjelasan di atas dapat kita simpulkan bahwa fungsi dari uang yang terpenting adalah stadarnya bukan bentuk uang itu sendiri. Uang emas diterbitkan ole Raja Dinarius dari kerajaan Romawi. Uang emas sendiri memiliki nilai yang stabil. Hal ini juga berlaku untuk dirham yang berasal dari persia tepatnya dari keraan Sasanid. Oleh sebab itu walaupun bukan diterbitkan oleh negara Islam Rasululla SAW mempergunakannya sebagai alat tukar. ( Susanti, 2017 :34-35)

\section{Definisi Uang dalam Ilmu Konvensional}

Uang dalam ilmu ekonomi tradisional didefinisikan sebagai setiap alat tukar yang dapat diterima secara umum. Dalam ilmu ekonomi modern, uang didefinisikan sebagai sesuatu yang tersedia dan secara umum diterima sebagai alat pembayaran bagi pembelian barang-barang dan jasa-jasa serta kekayaan berharga lainnya sertauntuk pembayaran utang. (Abdul Mukhi, $2011: 1$ dalam fadilla, 2017 : 26-27) Ada beberapa macam fungsi uang antara lain :

1. Alat tukar atau medium of exchange yang dapat mempermudah pertukaran.

2. Satuan hitung (unit of account) digunakan untukmenunjukan nilai berbagai macam barang/jasa yangdiperjualbelikan, menunjukkan besarnya kekayaan, danmenghitung besar kecilnya pinjaman, juga dipakai untukmenentukan harga barang/jasa (alat penunjuk harga). 
3. Alat penyimpan nilai (valuta) karena dapat digunakan untuk mengalihkan daya beli dari masa sekarang kemasa mendatang.

4. Standar pembayaran dimasa mendatang (standar of demand payment). (Abdul Mukhi, 2011 : 2 dalam fadilla 2017: 26-27)

Para ahli Ekonomi sudah memnahas tentang standar sesbuah benda dapat di jadikan sebagai uang. Benda tersebut harus memenuhi beberapa persyaratan, syarat tersebun antara lain :

a. Harus diterima secara umum (acceptability).

b. Memiliki nilai tinggi atau dijamin keberadaannya olehpemerintah yang berkuasa.

c. Bahan yang dijadikan uang juga harus tahan lama (durability),

d. kualitasnya cenderung sama (uniformity),

e. jumlahnya dapat memenuhi kebutuhan masyarakat

f. tidak mudah dipalsukan (scarcity).

g. Harus mudah dibawa (portable) dan mudah dibagi tanpa mengurangi nilai (divisibility)

h. memiliki nilai yang cenderung stabil dari waktu ke waktu (stability of value). (Abdul Mukhi, $2011: 2$ dalam fadilla 2017)

Adapun jenis uang sendiri, dibagi menjadi beberapa macam yaitu menurut bentuknya, jenisnya bahan pembuatnya dan nilainya. Pembagian uang menurut jenisnya antara lain :

1. uang kartal (sering pula disebut sebagai (common money) adalah alat bayar yang sahdan wajib digunakan oleh masyarakat dalam melakukan transaksi jual-beli sehari-hari.

2. uang giral, adalah uang yang dimiliki masyarakat dalam bentuk simpanan (deposito)yang dapat ditarik sesuai kebutuhan. (Abdul Mukhi, 2011 : 3 dalam fadilla 2017)

\section{Sejarah Pencetakan Uang}

\section{a. Masa Rasulullah SAW}

Ketika Nabi Muhamad SAW diutus sebagai nabi dan Rasul, beliau menetapkan apa yang sudah menjadi tradisi penduduk mekkah. Beliau memerintahkan penduduk madinah untuk mengikuti ukuran timbangan penduduk 
Mekkah ketika itu mereka bertransaksi menggunakan dirham dalam jumlah bilangan bukan timbangan Rasulullah SAW bersabda :

"Timbangan adalah timbangan penduduk Mekkah sedangkan takaran penduduk Madinah"

Karena adanya perintah tersebut adanya pernedaan ukurn dirham di Persia karena terdapat 3 bentuk pencetakan uang yaitu :

a. Ukuran 20 karat

b. Kuran 12 karat

c. Ukuran 10 karat

Lalu ditetapkan dalam dirham Islam menjadi 14 karat denan membagi semuanya dengan rata-rata 3. Dengan perhitungan $\frac{20+12+10}{3}=14$

Nilai ini sama dengan nilai daniq seukuran dengan 7 mitscal di masa sekarang disamakan dengan gram.

\section{b. Masa Khalifah Rasyidin}

a. Abu Bakar

Pada masa pemetrintahan Khalifah Abu Bakar keadaan bentuk uang masih sama dengan masa Rasulullah SAW yaitu menggunakan mata uang Dinnar dan dirham.

b. Ummar Bin Khatab

Pada tahun $18 \mathrm{H}$ yaitu pada masa Khalifah Ummar di cetaklah dirham Islam. Khalifah Ummar melakukan hal- hal pentingdalam masalah uang seperti:

1) Pencetakan uang dirham dengan ciri-ciri yang menunjukkan keIslaman. Pada masa ini bentuk uang hampir sama dengan persia namun ada tulisan tambahan seperti "Al-hamdulillah".

2) Ditetapkan standar dirham yaitu sama dengan dinnar 1 dirham sama dengan 7/10 dinar atau setara dengan 2,97 gram dengan landasan standar nilai dinar sebesar 4,25 gram.

3) Dibuat uang dalam bentuk lain yaitu kulit hewan dengan pemikiran bahwa bahan dasar kulit hewan mudah dibawah, namu hal itu diurungkan karena banyak sahabat yang tidak setuju dengan pertimbangann bahwa kulit tidak dapat dijadikan standar penilaian karena harga kulit berfluktuasi. Akhirnya 
khalifah Ummar menetapkan standar koin dinnar dan dirham berat 7 dinnar sama dengan 10 dirham. Standar dinar emas memakai 22 karat dengan berat 4,25 gram. Sedangkan dirham harus menggunakan perak murniseberat 3,0 gram. Keputusan ini telah ditetapkan para ulama pada masa itu.

c. Utsman bin Affan

Pada masa ini perkembangan percetakan uan dinar dan dirham dengan memodifikasinys dengan menggunakan simbol-simbol Isla. Didalam uang dinnar tersebut tertulis "Allahu akbar". Di batas koin terdapat kata-kata aksara kuffi yang artinya "Rahmat dengan asmaAllah, dengan asma Tuhanku bagi Allah daan Muhammad.

d. Ali bin Abi Thalib

Pada masa khalifah Ali pencetakan dirham mengikuti khalifah Ustman bin affan hanya saja menuliskan di salah satu lingkarannya kalimat Bismillah, Bismillah Rabbi, dan Rabiyallah dengan tulisan kufi.(Susanti, 2017 : 37-39)

\section{c. Masa Bani Dinasti Umayah}

Pencetakan uang pada Dinasti Umayah semenjak Muawiyah bin Abi Sofyan masih meneruskan model Sasanid dengan menambahkan beberapa kata tauhid. Pada tahun $76 \mathrm{H}$ Andul Malik bin Marwan membuat mata uang yang bernafaskan model Islam tersendiri. Abdul Malik Mampu merealisasikan stebilitas politik dan ekonomi, mengurangi pemalsuan dan manipulasi terhadap mata uang. Pada masa Abdul Malik dan Hisyam bin Abdul Malik bahkan beliau menghukum orang yang memalsukan uang dengan hukuman 1000 cambuk dan jumlahnyan lebih dari 100 orang. Pada Akhirnya Dinnar pada Dinasti Ummayyah terkenal halus, akurat dan murni. (Susanti, 2017 ; 39)

\section{d. Pada Masa Abbasiah dan setelahnya.}

Pada masa Abbasiyahpencetakan uang masihmelajutkan sistem pencetakan pada masa Ummayah.Pada masa Al-Saffah dirham pada mulanya dikurangi menjadi satu butir kemudian dikurangi satu butir kemudian dilanjutkan dengan 2 butir, terus berlanjut pada masa Abu jafar Al-Mansur. Pada masa 
Dinansti Fathimiyah, dirham-dirham campuran sangat banyak menyebabkan banyaknya dirham campuran sehingga nilanya menjadi turun.

Pada masa Shalahudian Al-Ayyubi bahan baku emas sudah tidak mencukupi untuk pencetakan dinar hal ini disebabkan karena peperangan. Karena mata uang utama tidak murni begitupun jua dengan perak bahkan separuhnya adalah tembaga maka pencetakan uang seperti ini terus berlanjut pada masa Bani Ayub.

Pada masa pemerintaham Mamalik pencetakan uang tembaga tersebar luas. Bahkan raja Al-Zhahir Barquq dan anaknya Fajr, uang tembaga menjadi mata uang utama karena :

1. Penjualan perak di negara eropa

2. Impor tembaga dari negara-negara eropa

3. Meningkatnya konsumsi perak (Susanti, 2017 : 37-39)

\section{Berlakunya Uang Kertas}

Pada tahun 1839 pemerintahan Usmaniyah menerbitkan mata uang yang berbentuk kertas banknote dengan nama gaima, namun nilainya terus merosot dikarenakan rakyat tidak mempercainya. Pada perang dunia 1 tahun 1914 Turki dan negara-negara lainnya memberlakukan uang kertas sebagaialat pembayaran yang sah dan membatalkan berlakuknya uang emas dan perak. Sejak saat itu uang kertas diakui sebagai alat pembayaran diseluruh dunia ( Rozalinda dalam Susanti, 2017 : 41)

Sejak saat itu uang kertas diakui sebagai alat pembayaran yang sah sekaligus diakui sebagai bentuk dari sebuah kekayaan. Uang kertas sendiri memiliki beberapa kelebihan dan kekurangan. Adapun kelebihan uang kertas :

a) Mudah di bawa

b) Biaya penerbitan lebih kecil dari pada uang logam

c) Dapat dipecah dalam jumlah berapapun

Selain kelebihan uang kertas juga memiliki beberapa kekurangan antara lain :

a) Tidak terjaminnya Stabilitas nilai tukar

b) Percetakaan uang kertas dalam jumlah berlebihan akan menimbulkan inflasi

c) Jika nilai uang turun maka harga akan naik. 


\section{Reformasi Alat tukar di Masa Sekarang}

Majunya teknologi pada masa sekarang menyebabkan banyaknya perubahan dalam sistem pembayaran dan transaksi jual-beli. Sekarang banyak bermunculan alat taknologi yang digunakan untuk pembayaran termasuk uang. Pada masa kini untuk pembayaran menggunakan E-Money ( Elektronik Money).

Ada beberapa definisi dari uang elektronik. Menurut Bank for International Settlement (BIS) tahun 1996uang elektronik adalah "stored value or prepaid products in which a record of thefunds or value available to a costumer is stored on an elektronic device in the costumer's possession". (Bank for Internatinal Settlement, 1996 dalam Muamar dan Salman 2017 : 76). Adapun adalah Menurut Peraturan Bank Indonesia Nomor 16/08/PBI/2014 tentang Perubahan Atas Peraturan Bank Indonesia Nomor 11/12/PBI/2009 "Uang Elektronik (Electronic Money) adalah alat pembayaran yang memenuhi unsur antara lain

(1) Diterbitkan atas dasar nilai uang yang disetor terlebih dahulu kepada penerbit;

(2) Nilai uang disimpan secara elektronik dalam suatu media server atau chip;

(3) Digunakan sebagai alat pembayaran kepada pedagang yang bukan merupakan penerbit uang elektronik tersebut;

(4) Nilai uang elektronik yang dikelola oleh penerbit bukan merupakan simpanan sebagaimana dimaksud dalam undang-undang yang mengatur mengenai perbankan”.(Pranoto dan Salma, $2018: 25$ )

\section{Tujuan Penggunaan E-Money}

1. Untuk mempermudah proses pembayaran dengan mempermudah transaksinya.

2. Mengoptimalkan daya beli masyarakat dan sekaligus menigkatkan kemampuan daya beli masyarakat

3. Meningkatkan pendapatan pemerintah (Sofyan, $2017: 4$ )

\section{Bentuk-Bentuk Uang Elektronik}

1. Beradasarkan Medianya:

a) uang elektronik yang nilai uangnyaselain dicatat pada media elektronik yang dikelola oleh penerbit juga dicatat dalam mediaelektronik yang dikelola oleh 
pemegang. ((Hidayati, Nuryanti, Firmansyah, Fadly, \& Darmawan,2006, hal 7. dalam Muamar dan Salman 2017 : 77)

b) uang elektronik yang nilai uang elektroniknya hanya dicatat pada mediaelektronik yang dikelola oleh penerbit (Bank Indonesia, 2009 hal 2dalam Muamar dan Salman 2017 : 77)

\section{Berdasarkan Masa Berlakunya}

a) Reloadable adalah uang elektronik yang dapat dilakukan dengan melakukan pengisian ulang,

b) Disposable uang elektronik yang tidak dapat diisi ulang (Bank Indonesia, 2009 hal. 27 dalam Muamar dan Salman 2017 : 77)

3. Berdasarkan jangkauanpenggunaanya uang elektronik dibedakan menjadi dua:

a) Single-Purpose adalah uang elektronikyang hanya dapat digunakan untuk transaksi pembayaran atas kewajiban yang timbul dari satujenis transaksi ekonomi, dan

b) Multi-Purpose adalah uang elektronik yang dapat digunakan untuk berbagai jenis transaksi ekonomi (Rivai, Veithzal, \& Idroes, 2001,hal 1367-1368 dalam Muamar dan Salman 2017 : 77)

4. Berdasarkan Jenisnya

Ada beberapa macam jenis uang elektronik, jenis-jenis uang elektronik tersebut antara lain :

a) Penerbitan dan pengisian ulang uangelektonik. Sebelum penerbit menerbitkan uang elektronik, penerbit akan mengisi nilai uangterlebih dulu ke dalam media elektronik yang akan digunakan sebagai uang elektronik.Kemudian apabila nilai uang elektronik yang dipegang oleh pemegang sudah habis, pemegangdapat melakukan pengisian uang (top up)

b) transaksi pembayaran dengan uang elektronik pada prinsipnya dilakukan melaluipenukaran nilai uang yang ada di dalam uang elektronik dengan barang atau jasa antarapemegang dengan penjual dengan menggunakan protocol yang telah ditetapkan sebelumnya(Hidayati et al., 2006,hal : 10-11). 
106 | Fadilla. Pengaruh Penggunaan Uang Sejak Masa Rasulullah SAW Sampai Sekarang

\section{SIMPULAN}

Hasil penelitian ini menunjukkan bahwa :

1. Pada masa Rasulullah pertukaran uang menggunakan emas dan perak (dinnar dan dirham) hal ini berlajut sampai pada masa khalifah dan Bani Umayah dan Abbasiyah. Pada

2. Masa Fathimiyah dirham-dirham campran banyak dijadikan uang. Pada masa Shalahudian Al-Ayyubi bahan baku emas sudah tidak mencukupi untuk pencetakan dinar hal ini disebabkan karena peperangan.

3. Akhirnya pada saat perang dunia pertama tahun 1914 Turki dan negara-negara lainnya memberlakukan uang kertas sebagaialat pembayaran yang sah dan membatalkan berlakuknya uang emas dan perak.

4. Pada masa sekarang dengan kecanggihan teknologi sudah banyak yang menggunakan uang elektronik (E-Money) dikarenakan lebih simpel dan mudah dalam penggunaannya.

\section{DAFTAR PUSTAKA}

Fadilla. 2016. Pengaruh Nilai Akuntansi Terhadap Pengelolaan Keuangan Mahasiswa (STEBIS IGM). Jurnal Ecoment Global. Vol.1 No.2

Aravik, Havis, 2016. Ekonomi Islam; Teori, Konsep dan Aplikasi Serta Pandangan Pemikir Ekonomi Islam dari Abu Ubaid Sampai Al-Maududi, Malang: Empat Dua.

Muamar, Afif dan Ari Salman Al-Farizi. 2017. Electronic money (e-money) dalam perspektif maqashid syariah. Journal Of Islamic Economics Lariba Vol. 3 isus : 2

Pranoto dan Salma Sekar Salsabila. 2018. Eksistensi Kartu Kredit Dengan Adanya Teknologi Elektronok Money sebagai Alat Pembayaran yang Sah. Privat Law. Vol 6 No. 1

Susanti, Resi. 2017. Sejarah Transformasi Uang dalam Islam. Jurnal Aqlam. Vol.2 No.1

Sofyan, Muhamad Abidin. 2017. Dampak Kebijakan E-Money di Indonesia Sebagai Sistem Pembayaran Baru. Surabaya: Universitas Negeri Surabaya. 